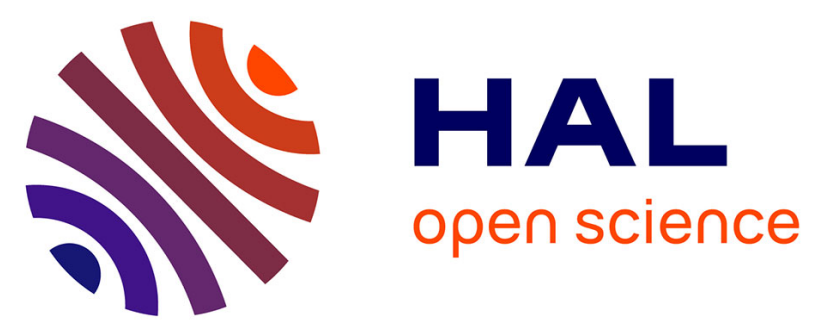

\title{
Comparison of stratospheric ozone profiles and their seasonal variations as measured by lidar and Stratospheric Aerosol and Gas Experiment during 1988
}

I. Stuart Mcdermid, Sophie Godin, Pi-Huan Wang, M. Patrick Mccomick

\section{- To cite this version:}

I. Stuart Mcdermid, Sophie Godin, Pi-Huan Wang, M. Patrick Mccomick. Comparison of stratospheric ozone profiles and their seasonal variations as measured by lidar and Stratospheric Aerosol and Gas Experiment during 1988. Journal of Geophysical Research: Atmospheres, 1990, 95 (D5), pp.5605-5612. 10.1029/JD095iD05p05605 . insu-03047218

\section{HAL Id: insu-03047218 \\ https://hal-insu.archives-ouvertes.fr/insu-03047218}

Submitted on 2 Feb 2021

HAL is a multi-disciplinary open access archive for the deposit and dissemination of scientific research documents, whether they are published or not. The documents may come from teaching and research institutions in France or abroad, or from public or private research centers.
L'archive ouverte pluridisciplinaire HAL, est destinée au dépôt et à la diffusion de documents scientifiques de niveau recherche, publiés ou non, émanant des établissements d'enseignement et de recherche français ou étrangers, des laboratoires publics ou privés. 


\title{
Comparison of Stratospheric Ozone Profiles and Their Seasonal Variations as Measured by Lidar and Stratospheric Aerosol and Gas Experiment During 1988
}

\author{
I. Stuart McDermid and Sophie M. Godin ${ }^{1}$ \\ Jet Propulsion Laboratory, Table Mountain Facility, California Institute of Technology, Wrightwood \\ Pi-Huan Wang \\ Science and Technology Corporation, Hampton, Virginia
}

\section{PATrick McCormick}

Aerosol Research Branch, Atmospheric Sciences Division, NASA Langley Research Center, Hampton, Virginia

\begin{abstract}
A ground-based, high power, laser remote sensing system for measurements of stratospheric ozone concentration profiles has been in operation at the Jet Propulsion Laboratory Table Mountain Facility located in southern California, $+34.4^{\circ} \mathrm{N},-117.7^{\circ} \mathrm{W}$, since January 1988. The seasonal variations observed in the ozone profiles, during 1988 and as a function of altitude, are described here. These profiles are compared with those from the Stratospheric Aerosol and Gas Experiment (SAGE II) satellite instrument made within a radius of $1000 \mathrm{~km}$ from the lidar and also with the zonal mean measurements made in the band $34.4^{\circ} \pm 5^{\circ}$. Comparison with the proposed new CIRA ozone reference model has also been carried out. The seasonal variations, between $25 \mathrm{~km}$ and $50 \mathrm{~km}$, observed by the two instruments and indicated by the reference model are in good agreement.
\end{abstract}

\section{INTRODUCTION}

A laser remote sensing facility has been established at the Jet Propulsion Laboratory Table Mountain Facility (JPL TMF) located in southern California, $+34.4^{\circ} \mathrm{N},-117.7^{\circ} \mathrm{W}$, for the primary purpose of making long-term measurements of the stratospheric ozone concentration profile. It is anticipated that the operation of this facility over the next few years will provide a large data set sensitive enough to aid in the detection of trends in the ozone concentration. In addition to this primary objective this lidar facility will also have significant short-term scientific value. It will participate in correlative measurement and ground-truth programs with satellite instruments, such as described herein and in the future for instruments on board the Upper Atmosphere Research Satellite (UARS) and the Earth Observing System (EOS) space platforms. It may help in evaluating and possibly correcting the sensitivity changes that have been observed in the solar backscatter ultraviolet (SBUV) satellite ozone instruments caused by degradation of a diffuser plate during its lifetime in space. It will also enable the study of the diurnal, monthly, seasonal, and annual variability of the ozone profile in much greater detail than has previously been possible (at a single location).

One of the primary purposes of this study is to validate, by comparison, the lidar measurements. This paper presents the data obtained during the first full year of operation of the lidar

\footnotetext{
${ }^{1}$ Now at Service d'Aeronomie du CNRS, Paris.

Copyright 1990 by the American Geophysical Union.

Paper number 89JD02876.

0148-0227/90/89JD-02876\$05.00
}

and compares them with SAGE II measurements and with the proposed CIRA reference atmosphere ozone model [Keating and Pitts, 1987; Keating et al., 1987]. The ozone reference model was developed by combining data from five satellite experiments, Nimbus 7 limb infrared monitor of the stratosphere, (LIMS), Nimbus 7 SBUV, AE-2 Stratospheric Aerosol and Gas Experiment (SAGE), and Solar Mesosphere Explorer ultraviolet spectrometer (SME UVS) and infrared spectrometer (SME IR), obtained during the period November 1978 to December 1983. Comparison of this model with balloon and rocket measurements has shown good agreement, within $10 \%$, below 0.2 mbar ( $\sim 60 \mathrm{~km})$. Also, ozonesonde and Umkehr measurements made at fixed stations show better than $10 \%$ agreement with the zonal mean model values. The error budget of the SAGE II instrument has been considered in depth, and ozone profile measurements have been validated through correlative measurements with coincident rocket ozone sondes (ROCOZ-A) and electrochemical concentration cell (ECC) sonde measurements [Cunnold et al., 1989]. Unlike most satellite instruments, which measure ozone mixing ratio as a function of atmospheric pressure, the SAGE II instrument directly measures ozone number density as a function of absolute altitude. This is the same as the lidar, and therefore it is not necessary to use a temperature-density-pressure profile to convert the measurements before comparison. The lidar and SAGE II instruments, together with the radar-tracked ROCOZ-A sonde, provide the opportunity for direct comparison of ozone profiles without the uncertainty introduced when the measurements have to be converted to or from pressure units. In addition, the SAGE II measurement technique, owing to its inherent ability to self calibrate each profile and to provide high vertical resolution, provides an opportunity to 
validate the lidar technique against probably the most accurate spacecraft remote sensor of stratospheric ozone [World Meteorological Organization, 1989].

\section{EXPERIMENT}

The ultraviolet, differential absorption lidar (DIAL) technique has been used to measure ozone concentration profiles between $20 \mathrm{~km}$ and $50 \mathrm{~km}$ altitude. The lidar system and its operation have been fully described elsewhere [McDermid, 1987; I. S. McDermid et al., Ground-based laser DIAL system for long-term measurements of stratospheric ozone, submitted to Applied Optics, 1989] and only a brief description is given here. A high-power $\mathrm{XeCl}$ excimer laser is used to provide the probe wavelength at $308 \mathrm{~nm}$. The reference wavelength, $353 \mathrm{~nm}$, is generated by stimulated Raman shifting of a portion of the fundamental beam, in a highpressure (400 psig) hydrogen cell. Thus the two wavelengths are transmitted simultaneously in time and, by careful alignment, in space. The backscattered radiation is collected with a 90-cm-diameter telescope, and the two wavelengths are separated by a series of dichroic beamsplitters and interference filters. The signal is then measured using photomultipliers and photon counting techniques. To derive an ozone profile, the lidar signal is averaged for $10^{6}$ laser pulses, which takes approximately 2 hours. The experiment is usually commenced at the end of astronomical twilight, which occurs 1.5 to 2 hours after sunset depending on the season, and normally only one ozone profile is measured per night.

To derive the ozone profile, a low-pass derivative filter is applied to the background corrected signal and the slope (derivative) of the signal is computed as a function of range. As the altitude increases the range resolution of the measurement has to be degraded to limit the increase in the statistical error related to the rapid decrease of the signal at both wavelengths. To effect this compromise, the cutoff frequency of the filter, which is mathematically related to the effective range resolution, is made to vary with the altitude. The ozone number density is obtained from the difference of the derivatives of the signals recorded for each wavelength, divided by the ozone differential absorption cross section. Corrections are made for the Rayleigh scattering and extinction terms, but no aerosol corrections are made. In the stratosphere the term related to aerosol extinction is negligible with respect to the other terms, $<1 \%$ above $20 \mathrm{~km}$, and so the influence of aerosols on the measurement relates mainly to the scattering term. The DIAL analysis assumes that this is the same for both wavelengths, but because of the low number of aerosols in the stratosphere and the very small ratio of aerosol-to-Rayleigh backscattering, this effect is also minimal. In this particular lidar implementation the largest source of error has been found to be associated with the determination of the background signal. Even small errors in the background estimations are seen to have significant impact on the derived ozone profile above $\sim 45$ $\mathrm{km}$, and these errors must be added to the calculated statistical errors in this region.

Prior to July, 1988 the lidar receiver system employed only one channel for each wavelength, and the altitude range of the lidar measurement was limited to $30 \mathrm{~km}$ to $50 \mathrm{~km}$, owing to dynamic range restrictions with the photomultipliers and

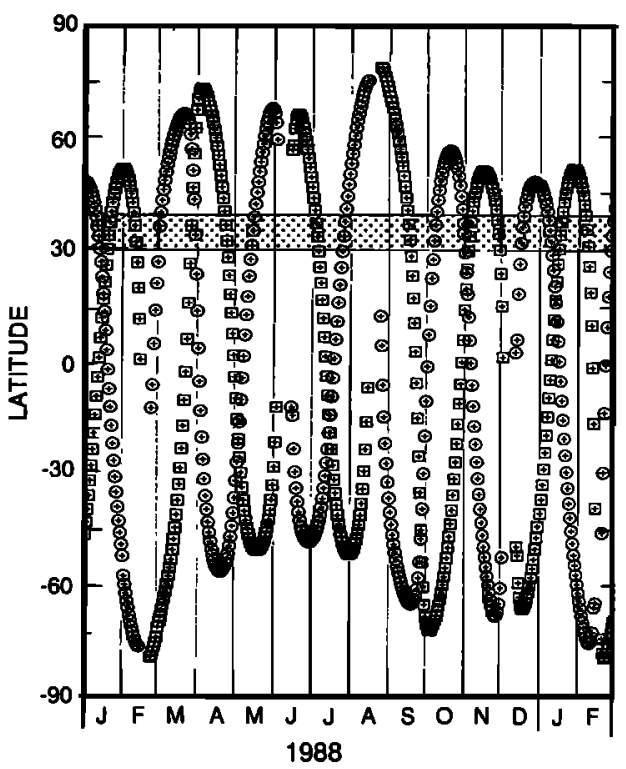

Fig. 1. SAGE II orbit and measurement locations during 1988. The circles indicate an occultation measurement at sunrise and the squares, a measurement at sunset. Measurements made within the shaded area were used in the zonal mean comparisons.

photon-counting system. At this point a second channel was added for each wavelength, to receive $\sim 10 \%$ of the returned signal and thus effectively increase the dynamic range by one decade; these channels allowed an ozone profile measurement between $20 \mathrm{~km}$ and $40 \mathrm{~km}$. Each wavelength pair, simply referred to as high channels and low channels, is analyzed independently. Thus two profiles are produced which overlap between $30 \mathrm{~km}$ and $40 \mathrm{~km}$. The two profiles normally agree within 1 or $2 \%$ in this region, and agreement within the error bars is always expected. If the profiles do not agree well, this is an indication of some problem, and experience has shown that this is most likely due to the background level calculation which can be adversely affected by misalignment of the transmitter-receiver and to the effects of a bright moon close to zenith. A composite profile is made up using the low-channel data from $20 \mathrm{~km}$ to $\sim 30 \mathrm{~km}$ and the high channel data from $\sim 30 \mathrm{~km}$ to $50 \mathrm{~km}$.

The SAGE II (Stratospheric Aerosol and Gas Experiment) instrument is a seven-channel, limb-scanning sun photometer using the solar occultation technique, and was launched onboard the Earth Radiation Budget Satellite (ERBS) in October 1984. Ozone concentrations are inferred from the $0.6 \mu \mathrm{m}$ radiances with a precision of $\sim 5 \%$ between 24 and 36 $\mathrm{km}$, degrading to $7 \%$ at $48 \mathrm{~km}$, for a vertical correlation distance of $3 \mathrm{~km}$. The latitude range extensively sampled is $65^{\circ} \mathrm{S}$ to $65^{\circ} \mathrm{N}$ with a roughly 1 month repeat cycle. The measurements at a particular latitude are grouped over several days, as can be seen in Figure 1 where the shaded band indicates the $34.4^{\circ} \pm 5^{\circ}$ zone of interest. The concept of a monthly mean is not appropriate for such grouping, and instead the approach used is to average the group of measurements about the mean day.

The altitude-range resolution and the typical experimental uncertainties are different for the lidar and the SAGE II instruments. For the lidar, the altitude resolution is a fixed function and is $\sim 1 \mathrm{~km}$ up to $30 \mathrm{~km}$, increasing to $3 \mathrm{~km}$ at 40 
TABLE 1. Dates of Ozone Profile Measurements

\begin{tabular}{|c|c|c|c|c|c|c|c|c|c|c|c|c|}
\hline & Jan. & Feb. & March & April & May & June & July & Aug. & Sept. & Oct. & Nov. & Dec. \\
\hline 1 & & & & & & & & HL & & & HL & HL \\
\hline 2 & & & H & & H & H & & HL & & & & HL \\
\hline 3 & & & & & H & H & & & & & $\mathrm{HL}$ & \\
\hline 4 & & & & & & & & & & $\mathrm{HL}$ & $\mathrm{HL}$ & \\
\hline 5 & & & & H & & & & & & & HL & HL \\
\hline 6 & HL & & & & & H & & & HL & HL & & \\
\hline 7 & & & & & & & & & & & HL & HL \\
\hline 8 & & & H & & & & & HL & & & $\mathrm{HL}$ & $\mathrm{HL}$ \\
\hline 9 & HL & & & & H & H & & $\mathrm{HL}$ & & & & HL \\
\hline 10 & $\mathrm{HL}$ & H & & & H & & & & & $\mathrm{HL}$ & HL & \\
\hline 11 & $\mathrm{HL}$ & H & & & H & & & & & $\mathrm{HL}$ & $\mathrm{HL}$ & \\
\hline 12 & $\mathrm{HL}$ & $\mathrm{H}$ & & & H & & & & H & $\mathrm{HL}$ & & HL \\
\hline 13 & HL & $\mathrm{H}$ & & & & & H & & & & & HL \\
\hline 14 & & $\mathrm{H}$ & & & & & H & & H & $\mathrm{HL}$ & & $\mathrm{HL}$ \\
\hline 15 & & H & & & & & & & & & HL & \\
\hline 16 & $\mathrm{HL}$ & H & & & & & & & & & $\mathrm{HL}$ & \\
\hline 17 & $\mathrm{HL}$ & & & & & & & & & HL & HL & \\
\hline 18 & $\mathrm{HL}$ & & & H & H & & H & $\mathrm{HL}$ & & $\mathrm{HL}$ & $\mathrm{HL}$ & HL \\
\hline 19 & $\mathrm{HL}$ & & & & H & & H & & H & $\mathrm{HL}$ & & \\
\hline 20 & & & & & & H & & & & $\mathrm{HL}$ & & \\
\hline 21 & & & & & & H & & & & HL & & HL \\
\hline 22 & & & & & & & & & H & $\mathrm{HL}$ & & \\
\hline 23 & & & & & H & & & & & $\mathrm{HL}$ & & \\
\hline 24 & & & H & & & & & & & $\mathrm{HL}$ & & \\
\hline 25 & $\mathrm{HL}$ & & & & & & & & & HL & & \\
\hline 26 & $\mathrm{HL}$ & & & H & H & & & & & $\mathrm{HL}$ & & \\
\hline 27 & $\mathrm{HL}$ & & & & $\mathbf{H}$ & & & & & $\mathrm{HL}$ & & \\
\hline 28 & & & & & & H & HL & & & & & \\
\hline 29 & & & & H & & H & & & & & HL & HL \\
\hline 30 & $\mathrm{HL}$ & & & & H & & & HL & & HL & HL & HL \\
\hline 31 & & & & & & & & $\mathrm{HL}$ & & $\mathrm{HL}$ & & \\
\hline
\end{tabular}

The date refers to the evening that the experiment began, even if it continued past midnight. $\mathrm{H}$ and $\mathrm{L}$ indicate whether data are available from the high channels $(30 \mathrm{~km}$ to $50 \mathrm{~km})$ and low channels $(20 \mathrm{~km}$ to $40 \mathrm{~km})$, respectively. Because of the limited number of experiments in January 1988, and also the fact that only high channel data were available at that time, the results from January 1989 have been used in this paper and are indicated in this table.

$\mathrm{km}$ and to $7.5 \mathrm{~km}$ at $50 \mathrm{~km}$. The uncertainty, statistical error, is dependent on a number of factors. The most important of these are the clarity of the atmosphere, particularly the troposphere, and the output power of the laser system. Since both of these factors vary from day to day, there is not a typical single value for the statistical error, but there is a normal range. Up to $35 \mathrm{~km}$ altitude the error is $\leq 1 \%$ and increases to $2-4 \%$ at $40 \mathrm{~km}$. At $45 \mathrm{~km}$ and above, the uncertainties in the lidar measurement increase rapidly from $\sim 3-10 \%$ at $45 \mathrm{~km}$ to $10-25 \%$ at $50 \mathrm{~km}$. Also, at these altitudes the calculated ozone concentration is very sensitive to the background level, and significant biases, toward higher ozone values, have been observed in measurements taken on nights when the moon was bright and close to zenith. Some of these points can be seen in the $50 \mathrm{~km}$ plot of Figure 3. This problem only occurs at the highest altitudes, above $45 \mathrm{~km}$, and does not affect the profile at lower altitudes. For the purposes of this comparison no data points have been omitted from the record even though it would be justified to omit the points at $50 \mathrm{~km}$, and to some extent 45 $\mathrm{km}$, that were obtained under conditions of high background moonlight.

\section{RESULTS}

During the year, from February 1988 through January 1989,111 ozone concentration profiles were recorded between $30 \mathrm{~km}$ and $50 \mathrm{~km}$ and of these, 68 measurements also included ozone profiles down to $20 \mathrm{~km}$ altitude. The dates of the ozone profile measurements made by the lidar instrument are shown in Table 1. Owing to the uneven distribution of these measurements through the year, some caution must be used when considering yearly means as these will be biased to those months with the greater numbers of measurements, which for this data set are the months October to January.

The lidar data were first compared with two ozone reference models, the Krueger and Minzner [1976] mid-latitude ozone model for the U.S. Standard Atmosphere (1976) and the Keating and Pitts [1987], Keating et al. [1987] reference model for CIRA. The results are shown in Figure 2. The individual lidar data points were averaged on a monthly basis and are shown by the solid lines in Figure 2. The $1 \sigma$ standard deviation of these measurements is indicated by the shaded areas. The Krueger and Minzner [1976] model provides an estimate of the mean annual ozone concentration for an effective latitude of $45^{\circ} \mathrm{N}$. No attempt has been made to adjust this model to $34^{\circ} \mathrm{N}$, and the ozone values are shown by the dotted lines in Figure 2. The Keating and Pitts [1987], Keating et al. [1987] model gives monthly zonal mean ozone concentrations for $10^{\circ}$ latitude increments, and these data have been interpolated to provide values corresponding to $34^{\circ} \mathrm{N}$ and are shown by the dashed line in Figure 2 .

The lidar results were next compared with measurements made by the SAGE II. For these comparisons, only SAGE II 

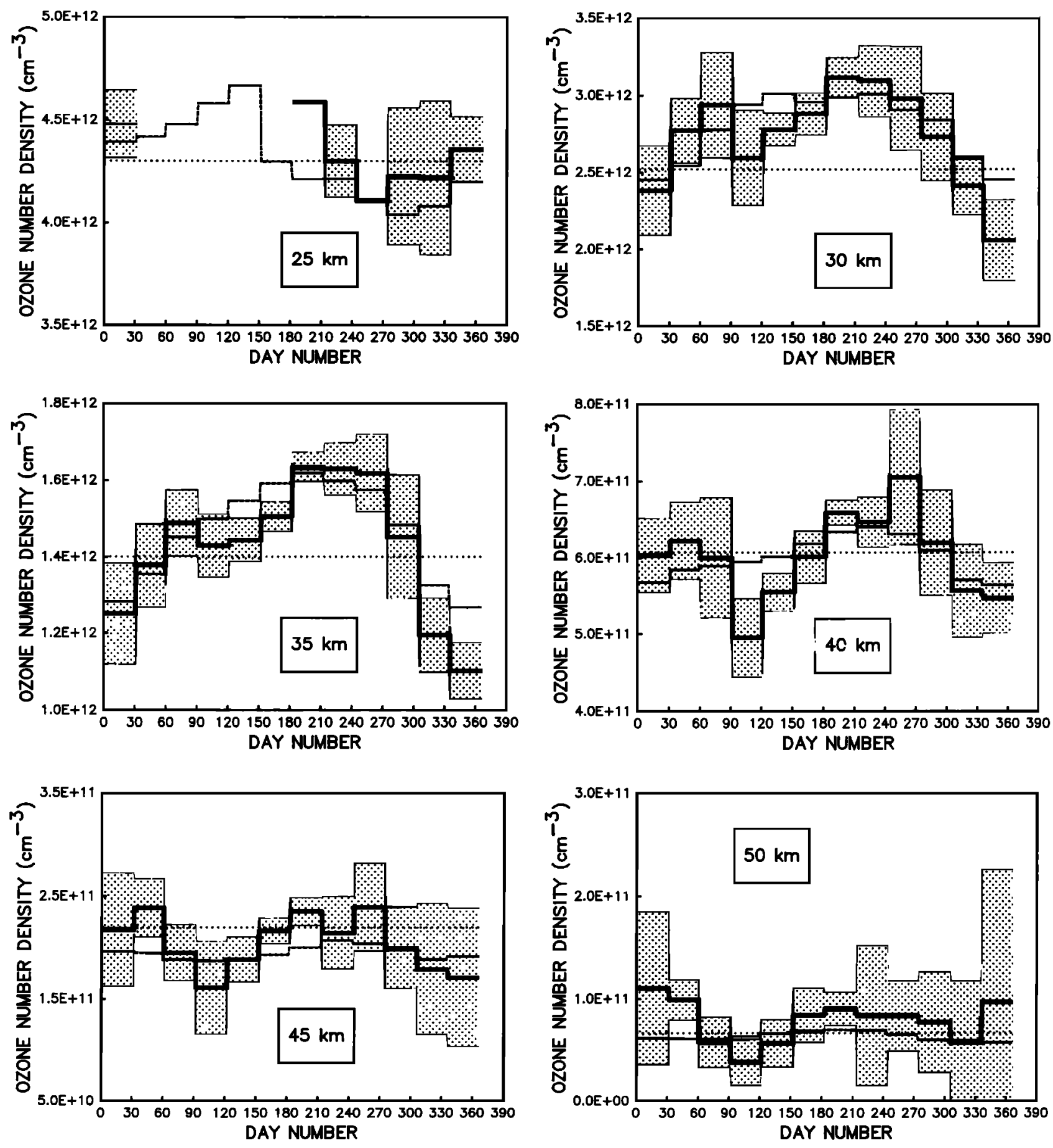

Fig. 2. Comparison of the lidar monthly means, indicated by the solid line and with $1 \sigma$ standard deviation indicated by the shaded area, compared with the monthly values at $34^{\circ} \mathrm{N}$ from the CIRA reference atmosphere, shown by the dashed line, and compared with the U.S. Standard Atmosphere (1976), represented by the dotted line.

measurements made within a radius of $1000 \mathrm{~km}$ from the lidar site were considered. For the same period as the lidar experiments, February 1988 to January 1989, there were 36 SAGE II measurements that met this criterion. However, none of the measurements were at precisely the same location and, since the SAGE II is a sun-observing instrument and the lidar operates only at night, the measurements are never made at the same time. The mean location of the 36 SAGE II measurements considered was $+35.0^{\circ} \mathrm{N}$, $-116.9^{\circ} \mathrm{W}$, compared to the lidar location at $+34.4^{\circ} \mathrm{N}$, $-117.7^{\circ} \mathrm{W}$, and the mean distance between the measurements was $715 \mathrm{~km}$. The individual data points are shown in Figure 3 where the open circles are the SAGE II measurements and the crosses are the lidar measurements.

The closest measurements were made on October 31 , 1988, when the SAGE II made a sunrise measurement at $34.48^{\circ} \mathrm{N},-114.94^{\circ} \mathrm{W}$, which is $240 \mathrm{~km}$ essentially directly east of the lidar. For this SAGE II sunrise measurement there were lidar measurements made during both the night before and the night after, and therefore these data provide 

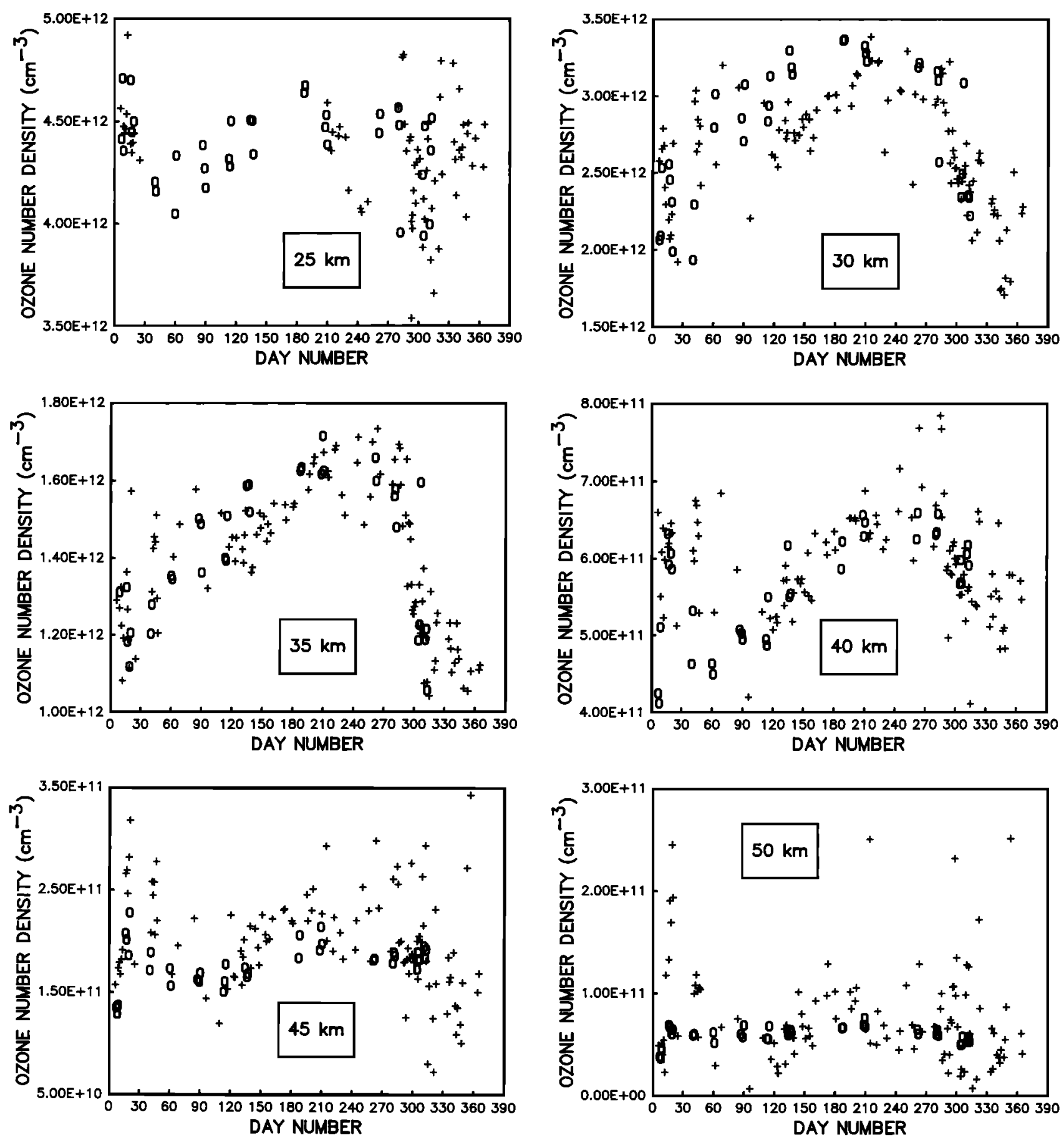

Fig. 3. Comparison of individual lidar measurements (crosses) and individual SAGE II measurements made within $1000 \mathrm{~km}$ of the lidar (circles).

the best upportunity for a detailed one-to-one comparison. To enable direct comparison, the lidar data were interpolated, using a cubic spline routine, to obtain ozone concentrations at the same altitudes as the SAGE II profile. The three profiles, two lidar and one SAGE II are shown in Figure 4. The logarithmic and linear scales are used to show the differences more clearly at high and low altitudes, respectively. Table 2 compares these profiles quantitatively, and it can be seen that for most of the range the agreement is better than $5 \%$. However, there are some features which can be seen in the profiles in Figure 4 where the difference is greater, reaching a maximum of $\sim 19 \%$. It should be noted that this comparison represents one of the best cases. Even for measurements within $1000 \mathrm{~km}$ of each other the profiles sometimes show significant differences which have been assumed to be due to the different location, primarily latitude, and different airmasses.

Finally, the lidar data were compared with the zonal mean of the SAGE II measurements within the band $34.4^{\circ} \pm 5^{\circ} \mathrm{N}$. For each mean day, up to 36 individual SAGE II measurements were averaged. Figure 5 shows these means, and their standard deviations, overlaid on the lidar monthly means. 

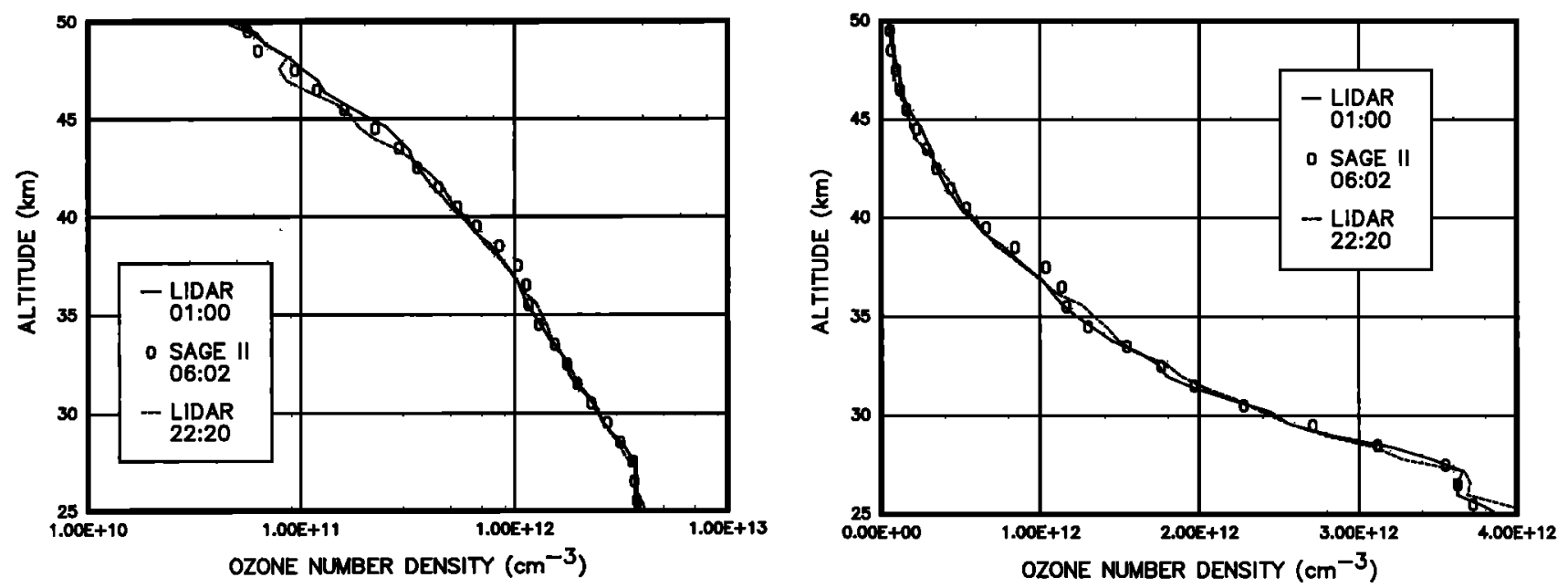

Fig. 4. Comparison of SAGE II and lidar ozone profiles measured on October 31, 1988. These represent the measurements closest in both time and location for the entire year. The times (PDT) of the measurements are indicated on the plots. The quantitative differences between these profiles are given in Table 2.

\section{Discussion}

The overall agreement between the lidar and SAGE II data sets, and the CIRA ozone reference model is very good. As is to be expected, the best agreement is found between the individual lidar measurements and SAGE II measurements made within $1000 \mathrm{~km}$ of JPL TMF, although the agreement between the lidar and the SAGE II zonal means is also very good for $30 \mathrm{~km}$ and higher altitudes as also might be anticipated because of the inherent greater variability in ozone below $30 \mathrm{~km}$ where dynamics dominate photochemistry. Also, one-to-one comparisons show agreement to better than $5 \%$ over most of the range when the measurements were almost simultaneous in time and space.

An attempt to quantify the overall agreement between the SAGE II and lidar measurements has been made by calculating a yearly average ozone concentration for each altitude and instrument. For SAGE II the 36 measurements made within $1000 \mathrm{~km}$ of the lidar were simply averaged. For the lidar the monthly means were averaged instead of the individual points in an attempt to eliminate some of the biases caused by different numbers of measurements in each month. The results are shown in Table 3 . At 45 and $50 \mathrm{~km}$,

TABLE 2. Comparison of SAGE II and Lidar Ozone Profiles Measured on October 31, 1988

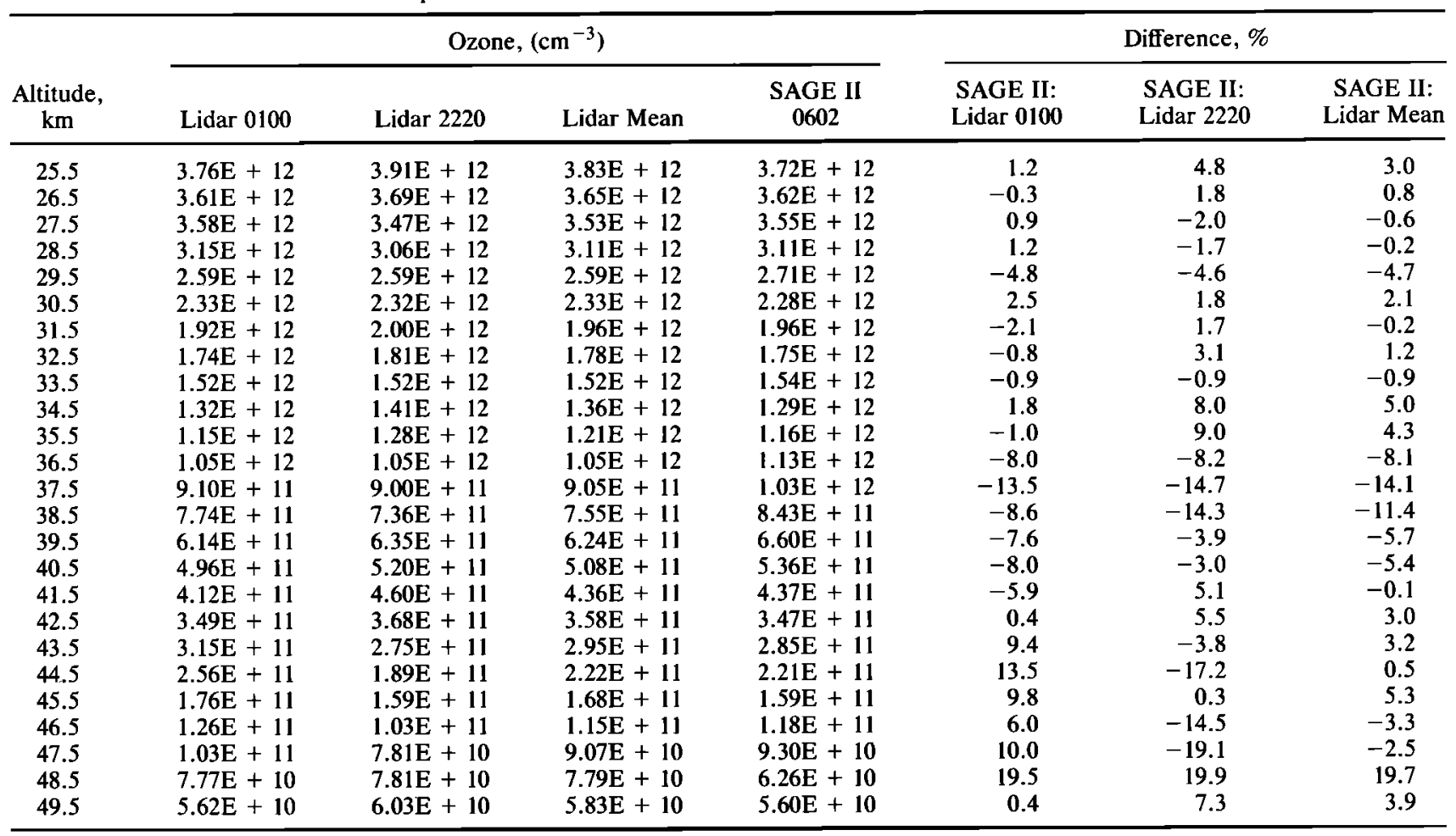

Read $3.76 \mathrm{E}+12$ as $3.76 \times 10^{12}$. 

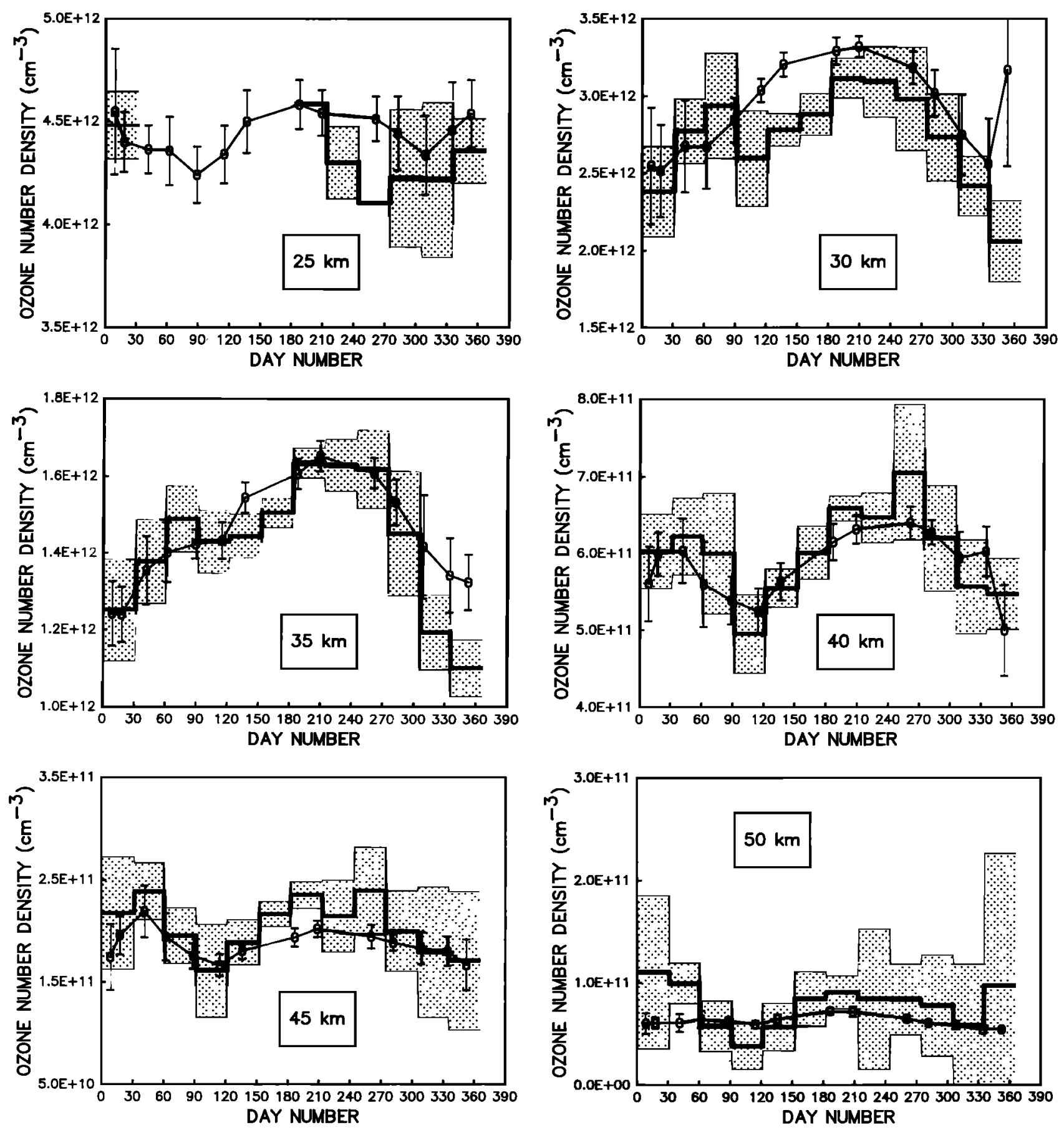

Fig. 5. SAGE II zonal mean values and $1 \sigma$ standard deviation (circles and error bars) overlaid on the lidar monthly means and $1 \sigma$ standard deviation (solid line and shaded area).

some of the difference may be attributable to some of the lidar data having too high ozone values due to biases caused by moonlight (all data were considered in forming the averages). Also, there were no SAGE II measurements within $1000 \mathrm{~km}$ during June, August, and December. For all of the altitudes, June and August tend to be months with higher ozone concentrations, and their omission would tend to reduce the SAGE II yearly average.

The annual (AO) and semiannual (SAO) oscillatory behavior in the ozone concentration profile is clearly shown in Figures 3 and 4. Such time-periodic variations, as observed by SAGE II, have been described in detail by Wang et al. [1988] for the latitude bands $-45^{\circ}$ to $-35^{\circ},-5^{\circ}$ to $5^{\circ}$, and $35^{\circ}$ to $45^{\circ}$. Here, for $34.4^{\circ} \mathrm{N}$, we find a single AO peaking in July for $30 \mathrm{~km}$ and $35 \mathrm{~km}$, similar to that observed by Wang et al. [1988] for $40^{\circ} \mathrm{N}$. The peak-to-peak magnitude of this oscillation is greatest at $30 \mathrm{~km}$ and is of the order of 0.8 to $1.0 \times$ $10^{12}$ molecule $\mathrm{cm}^{-3}$. At 40,45 , and $50 \mathrm{~km}$ there is a double oscillation, SAO, with one maximum in February for all and with a second maximum, in September at $40 \mathrm{~km}$, a broad peak from July to September at $45 \mathrm{~km}$, and in July at $50 \mathrm{~km}$. This behavior is somewhat different to that observed from 
TABLE 3. Comparison of SAGE II and Lidar Yearly Average Ozone Concentration for Various Altitudes

\begin{tabular}{cccc}
\hline $\begin{array}{c}\text { Altitude, } \\
\text { km }\end{array}$ & $\begin{array}{c}\text { Lidar Yearly } \\
\text { Ozone } \\
\mathrm{cm}^{-3}\end{array}$ & $\begin{array}{c}\text { SAGE II } \\
\text { Yearly Mean } \\
\text { Ozone, } \\
\text { cm }^{-3}\end{array}$ & $\begin{array}{c}\text { Difference Lidar : } \\
\text { SAGE II, \% }\end{array}$ \\
\hline 30 & $2.73 \mathrm{E}+12$ & $2.77 \mathrm{E}+12$ & -1.5 \\
35 & $1.43 \mathrm{E}+12$ & $1.40 \mathrm{E}+12$ & 2.1 \\
40 & $6.02 \mathrm{E}+11$ & $5.65 \mathrm{E}+11$ & 6.1 \\
45 & $2.05 \mathrm{E}+11$ & $1.79 \mathrm{E}+11$ & 12.7 \\
50 & $6.85 \mathrm{E}+10$ & $5.95 \mathrm{E}+10$ & 13.1 \\
\hline
\end{tabular}

Read $2.73 \mathrm{E}+12$ as $2.73 \times 10^{12}$.

1984 to 1987 by SAGE II at $40^{\circ} \mathrm{N}$ and is qualitatively more similar to the SAO observed at $0^{\circ}$ and $40^{\circ} \mathrm{S}$, although the phase is different. At $25 \mathrm{~km}$ the lidar data are limited, but the SAGE II data show a SAO with maxima in DecemberJanuary and June-July. This agrees, in terms of phase and period, with the previous SAGE II observations; however, the amplitude of the July peak is greater. Since this data set is limited to only a single annual cycle, some caution must be exercised not to overinterpret the conclusions.

We believe that this study confirms the power of the lidar technique for making accurate measurements of stratospheric ozone profiles. These comparisons should continue as a check on both sensors and as a validation in the determination of long term trends. It also demonstrates the ability to make correlative measurements with satellite instruments such as SAGE II, and also the future generation of instruments that will be carried onboard the UARS and EOS space platforms.

Acknowledgments. The work described in this paper was carried out at the Jet Propulsion Laboratory, California Institute of Technology, and at the Langley Research Center (LaRC) under contracts with the National Aeronautics and Space Administration. We are grateful for the assistance of Daniel Walsh, Oscar Lindqvist, and David Haner in the setup and operation of this lidar system and to G. M. Keating of NASA LaRC for providing us with a tape of the new COSPAR (CIRA) ozone reference model. We would also like to thank the National Research Council for the award of an associateship to S.M.G.

\section{REFERENCES}

Cunnold, D. M., W. P. Chu, R. A. Barnes, M. P. McCormick, R. E. Veiga, and D. A. Chu, Error analysis and validation of SAGE II ozone measurements, in Proceedings of the Quadrennial Ozone Symposium, edited by R. D. Bojkov and P. Fabian, p. 145, A. Deepak, Hampton, Va., 1988.

Cunnold, D. M., W. P. Chu, R. A. Barnes, M. P. McCormick, and R. E. Veiga, Validation of SAGE II ozone measurements, $J$ Geophys. Res., 94, 8447-8460, 1989.

Keating, G. M., and M. C. Pitts, Proposed reference models for ozone, Adv. Space Res., 7, 37-47, 1987.

Keating, G. M., D. F. Young, and M. C. Pitts, Ozone reference models for CIRA, Adv. Space Res., 7, 105-115, 1987.

Krueger, A. J., and R. A. Minzner, A mid-latitude ozone model for the 1976 U.S. Standard Atmosphere, J. Geophys. Res., 81, 4477-4481, 1976.

McDermid, I. S., Ground-based lidar and atmospheric studies, Surv. Geophys. 9, 107-122, 1987.

Wang, P.-H., M. P. McCormick, L. R. McMaster, S. Schaffner, and G. E. Woodbury, Time-periodic variations in stratospheric ozone from satellite observations, in Proceedings of the Quadrennial Ozone Symposium, edited by R. D. Bojkov and P. Fabian, p. 143, A. Deepak, Hampton, Va., 1988.

World Meteorological Organization, Report of the International Ozone Trends Panel-1988, Rep. 18, Geneva, in press, 1989.

S. M. Godin, Service d'Aeronomie du CNRS, Université Paris VI, 4 Place 75230 Paris Cedex 05, France.

M. P. McCormick, Aerosol Research Branch, Atmospheric Sciences Division, NASA Langley Research Center, Hampton, VA 23665.

I. S. McDermid, Table Mountain Facility, Jet Propulsion Laboratory, California Institute of Technology, Wrightwood, CA 92397.

P.-H. Wang, Science and Technology Corporation, 101 Research Drive, Hampton, VA 23666.

(Received July 24, 1989; revised September 5, 1989; accepted September 6, 1989.) 